\title{
The practice of climate change policy evaluations in the European Union and its member states: results from a meta- analysis
}

Noriko Fujiwara ${ }^{1 *}$, Harro van Asselt ${ }^{2}$, Stefan Bößner ${ }^{3}$, Sebastian Voigtt ${ }^{4}$ Niki-Artemis Spyridaki ${ }^{5}$, Alexandros Flamos ${ }^{5}$, Emilie Alberola ${ }^{6}$, Keith Williges ${ }^{7}$, Andreas Türk $^{7}$ and Michael ten Donkelaar ${ }^{8}$

\begin{abstract}
Background: This article presents the main findings from a meta-analysis of how climate change mitigation policy evaluations have been undertaken in the European Union (EU) and six of its Member States: Austria, Czech

Republic, France, Germany, Greece and the United Kingdom. It aims to provide insights into how policy evaluations are carried out and how those practices might be improved. As a first step, this article reviews the literature on the theory and practice of policy evaluations to guide our methodology and further analysis.

Results: Our sample of 236 policy evaluations in the EU and six Member States covers the period 2010-2016. Compared with the results of a similar meta-analysis carried out covering the period 1998-2007, formal evaluations commissioned by government bodies have been on the rise in 2010-2016. Most evaluations focus on effectiveness and goal achievement and usually forgo a deeper level of reflexivity and/or public participation in the evaluation process. The analysis also reveals the dominance of the energy sector in the sampled evaluations. The article finds that the low number of any policy evaluations in the agriculture, waste or land-use sectors is an area for further investigation.

Conclusions: The exercise of identifying, coding and categorising these evaluations for 7 years helps to provide insights into the potential use of ex-post evaluations in support of future EU legislative proposals and accompanying impact assessments. Having a good understanding on how a certain policy performed particularly according to evaluation criteria might form the basis for more ambitious climate change mitigation policies in the future. Our analysis further shows that it is crucial and urgent to allocate sufficient resources to the coverage of relatively under-represented sectors, such as land use, land-use change and forestry, and waste.
\end{abstract}

Keywords: Climate policy, Policy evaluation, Meta-analysis, European Union, EU member states

\section{Background}

The evaluation of climate change mitigation policy is crucial for understanding how well policies and measures work. Policy evaluation offers analysts insights in the functioning of policies and provides policymakers with much-needed information on how to improve them. In addition, policy evaluation can enhance the transparency of policy implementation,

\footnotetext{
* Correspondence: noriko.fujiwara@ceps.eu

${ }^{1}$ Centre for European Policy Studies (CEPS), Place du Congrès 1, 1000

Brussels, Belgium

Full list of author information is available at the end of the article
}

which is essential to gain citizens' support for those policies [1] and useful for private companies and investors to get a better understanding of the progress of those policies to support their decisions in favour of low-carbon investments.

The importance and necessity of climate policy evaluation were underscored by the Paris Agreement adopted in December 2015. The Paris Agreement puts in place a process in which countries pledge, in five-year cycles, nonlegally-binding Nationally Determined Contributions (NDCs). The main accountability mechanism to ensure countries live up to their promises consists of various

(C) The Author(s). 2019 Open Access This article is distributed under the terms of the Creative Commons Attribution 4.0 International License (http://creativecommons.org/licenses/by/4.0/), which permits unrestricted use, distribution, and 
review processes, notably a review of implementation by individual parties (i.e. through the "enhanced transparency framework" of Article $13^{1}$ ), and a review of global efforts towards long-term goals of the Agreement (i.e. the "global stocktake" of Article 14).

Since the early 1990s, and in line with the requirements under the United Nations Framework Convention on Climate Change (UNFCCC), the European Union (EU) has gained significant experience in monitoring and reporting greenhouse gas emissions, as well as the policies put in place to reduce emissions. Over time, the Union has strengthened its internal transparency mechanisms by requesting Member States to report on the impacts of these policies, adding an element of policy evaluation to the regulatory framework. Member States now have to report their progress on climate change policies under the EU's Monitoring Mechanism Regulation [2], while other policy areas such as renewable energy and energy efficiency also require Member States to submit national action plans and reports [1-3]. These requirements are streamlined into Integrated National Energy and Climate Plans under the new Energy Union Governance Regulation [4].

Although they are distinct practices, monitoring and reporting are closely intertwined with the evaluation of climate policies. Such climate policy evaluations can offer insights into a variety of aspects, including the amount of greenhouse gas emission reductions, the cost-effectiveness of policies, their social acceptance, or the coherence with other policies [5]. Climate policy measures - and thus also their evaluations - commonly address renewable energy deployment, switching to low-carbon fuels or electric vehicles and energy efficiency in buildings [34]. Systematic analysis of the information made available by these evaluations only recently began to draw attention and is usually fragmented across policy themes. A case in point is energy efficiency, where there has been a long tradition on evidence-based policy evaluations, with for instance the recent EU-funded EPATEE (Evaluation into Practice to Achieve Targets for Energy Efficiency) project providing a large repository of those across EU countries [35]. Nevertheless metaanalyses of evaluations targeting measures across policy themes are still largely lacking. A notable exception is Huitema et al. [6], which reports on a meta-analysis of 259 evaluations, covering the period from 1998 to 2007 for the EU and several EU Member States. ${ }^{2}$ This article offers a more recent application of this type of analysis,

\footnotetext{
${ }^{1}$ Parties to the Paris Agreement are to report on their emissions trends (through annual greenhouse gas inventories) and through biennial reports that need to indicate how much progress has been made in implementing and achieving their nationally determined contributions under the Agreement (see [31]).

${ }^{2}$ The Member States examined by Huitema et al. [6] are United Kingdom, Germany, Italy, Finland, Portugal, and Poland.
}

focusing on ex-post climate policy evaluations, to reflect more recent developments and gain updated insights into climate policy evaluation in the EU.

Through a systematic analysis of policy evaluations, the article aims to enhance the understanding of existing climate policy evaluation practices in the EU and Member States, juxtaposing the latter with broader policy developments at the EU and international level. The article first offers some background on the theory of policy evaluation and insights into EU evaluation practices. It then explains the methodology of our analysis. It summarises and discusses the results of the meta-analysis, and concludes with recommendations for EU policymakers and climate policy evaluators.

Policy evaluation can serve various functions. Aside from its key function of determining whether a policy can be considered effective [7], policy evaluation can help policymakers learn from their experiences and, where needed, correct and amend existing policies. Policy evaluation can further strengthen public accountability by demonstrating whether policies live up to policymakers' promises $[8,9]$. Furthermore, policy evaluation can be used as a management tool to review the performance of government departments [8].

Common to all those functions is some sort of value judgement based on certain criteria [10]. These value judgements add a layer of complexity, as they raise the question which criteria should be used to evaluate policies. Should an evaluation focus on goal attainment or should criteria such as "fairness" or "cost-effectiveness" be taken into consideration as well? And who decides against which of those values a policy is to be judged? There are no definitive answers to these questions, as they are highly context-specific: in a jurisdiction facing significant budgetary constraints, it may be appropriate to focus on the criterion of cost-effectiveness, while for another jurisdiction it may be more pertinent to focus on criteria such as the fairness and distributional impacts of a policy. While the criteria to be applied in policy evaluations are thus up for discussion, the policy evaluation literature gives some suggestions regarding good practices in policy evaluation. Policy evaluation should have a highly systematic approach that uses clear evaluation criteria [9]. Moreover, policy evaluation should go beyond simply assessing goal attainment and also ask whether specific policies have been adequate to their socio-cultural context $[12,13]$ to achieve their goal (e.g. whether policies are in line with existing norms and values; see [11]). In the same vein, Huitema et al. [6] argue that policy evaluations should also contain a certain degree of reflexivity (e.g. by questioning the objectives underpinning policies), that they should cater to the complexity of "wicked" problems such as climate change (e.g. allowing for more than one recommendation) and be participatory in nature (e.g. providing the opportunity for several stakeholder groups to voice their opinions on a 
given policy). In addition, Schoenefeld and Jordan [14] argue that, depending on whether policy evaluations are carried out or otherwise driven by government agents themselves or more by civil society stakeholders such as universities, NGOs and consultancies, results and outcome of the evaluation might vary, thus pointing to the importance of taking the evaluating entity into consideration [14].

Policy evaluation has become gradually more important in the EU. Since 2002, the European Commission has been committed to the EU agenda of "Better Regulation", which highlights, among others, the ex-ante impact assessments of policy initiatives, the monitoring and ex-post evaluation of existing policies as well as the importance of stakeholder consultation in these processes. ${ }^{3}$ More recently, in 2012, the European Parliament introduced ex-ante impact assessments by establishing a dedicated service within its administration. Since 2013, ex-post evaluations have been added to complete an entire legislative cycle from agenda setting to scrutiny of legislative proposals [15]. The growing recognition within the $\mathrm{EU}$ of the value of the evaluation process has resulted in an increasing demand for the evaluation of environmental policies and programmes [9], including evaluations in the area of climate policy.

As is the case for policy evaluation in general [16], it is challenging to evaluate climate policies, because it can be hard to identify clear policy outcomes, and policies often interact with each other $[9,17,18]$. This has also recently been recognised with respect to specific climate policy themes (e.g. energy efficiency), where a lack of quantitative data was highlighted as an impediment to evidence-based analysis required to distinguish effective from ineffective policy practices [36]. Within the EU, these barriers to an effective evaluation process are compounded by the complexity of the governance system [9]. Moreover, there are important political barriers for further strengthening evaluation and monitoring practices in EU Member States. For instance, they require financial resources that governments may be unwilling to allocate, and Member States may be unwilling to cede more powers to EU institutions for this function [19].

One of the most relevant pieces of EU legislation for climate change mitigation policy evaluations is the Monitoring Mechanism Regulation (MMR) [2]. ${ }^{4}$ The MMR requires Member States to report "quantitative estimates of the effect of policies and measures on emissions by sources

\footnotetext{
${ }^{3}$ https://ec.europa.eu/info/law/law-making-process/better-regulationwhy-and-how en last accessed on 28 March 2019; see also [21, 32]: 31. ${ }^{4}$ Regulation 525/2013/EU [2] is an update of the EU's Monitoring Mechanism Decision (Decision 280/2004/EC [33];). The MMR is not the only EU legislation that calls for the evaluation of the effects of policies and measures. As Hildén et al. [19] note, other Directives e.g. Article 22.1 of the Renewable Energy Directive (2009/28/EC) and Article 24.1 of the Energy Efficiency Directive (2012/27/EU) - likewise call for Member States to report on progress made in the implementation.
}

and removals by sinks of greenhouse gases" (Article $3.2(\mathrm{a})(\mathrm{v}),[2])$ and to report the following elements in their information on policies and measures (Article 13.1(c) (iii)(vii), [2]): the status of implementation of the policy or measure or group of measures; indicators to monitor and evaluate progress over time; quantitative estimates (both ex-post and ex-ante assessments) of the effects of policies and measures on emissions by sources and removals by sinks of greenhouse gases; estimates of the projected costs and benefits of policies and measures, as well as estimates of the realised costs and benefits of policies and measures; and all references to the assessments and the underpinning technical reports. These provisions are encouraging in that they call on Member States to provide both ex-ante and expost information on the effects of mitigation policies, and also encourage Member States to offer estimates of ex-ante and ex-post costs and benefits. Nevertheless, they also leave much discretion to the Member States, as indicated by the various mentions of the words "where appropriate" and "where available" (Article 13.1(c) (v)-(vii), [2]), as well as by the fact that Member States can opt to assess the effects of a group of measures. Initial reviews of reporting practices suggest that Member States thus far have hardly included ex-post assessments of the effects of policies and measures in their reports $[1,19]$.

Indeed, the necessary capacity to carry out ex-post evaluations is not equally developed throughout the EU. A 2009 study carried out in preparation for the MMR found that the EU15 Member States tended to have more experience in ex-post evaluations and more often have formalised monitoring and evaluation systems in place than the newer Member States ([20]: 14). These factors might have an impact on the capacity of newer Member States' to carry out ex-post evaluations.

All this is not to say that ex-post evaluations are not available for the EU and its Member States. Indeed, the European Environment Agency (EEA) seeks to go beyond formal evaluation procedures such as those carried out by or on behalf of the European Commission in the context of the Better Regulation agenda, adding value by evaluating policies within a more environment-specific context as well as those policies influencing environmental policies ${ }^{5}$ according to its autonomous mandate. It has also developed a conceptual framework for policy evaluation that builds on key policy evaluation criteria, with the aspiration to strengthen the tradition of carrying out policy evaluations within the EU and

\footnotetext{
${ }^{5}$ The EEA seeks to hold a dialogue about policies on changes in ecosystems, the production and consumption system, or the food, energy and mobility systems and engage in such a dialogue with the EEA member countries and the European Environment and Information Network (Eionet), European institutions, the environment evaluators community and interested evaluation professionals ([21]: 4).
} 
facilitate the dialogue between professional evaluators and evaluation users [21].

\section{Methods}

As a starting point, we made several important choices concerning the scope of our meta-analysis of climate policy evaluations.

The first choice was which geographical jurisdictions to include. Examining 28 Member States would have been challenging, considering time and resource constraints as well as language barriers. Drawing on the local expertise whilst securing diversity in the countries studied, we decided to include the three largest EU Member States (Germany, France, and the UK) as well as smaller Member States from Central and South-Eastern Europe (Austria, Czech Republic, and Greece), with varying emissions profiles. ${ }^{6}$ In addition, since important climate policy evaluations had been carried out at the EU level in [6], the EU was included as a separate jurisdiction.

The second scope-related choice concerned the time period of the analysis. The analysis by Huitema et al. [6] covered evaluations from January 1998 to March 2007. Reflecting climate policy developments in the period after the UNFCCC climate conference in Copenhagen and after the enactment of the EU's 2020 climate and energy package, both of which took place in 2009 , we decided to cover the period from January 2010 to December 2016.

The third choice concerned the eligibility of evaluations for the analysis. The number of climate policy evaluations is potentially large, and we sought to limit the number of evaluations by:

- Only examining ex-post evaluations, including studies that have both ex-ante and ex-post elements, and excluding purely ex-ante evaluations.

- Focusing only on climate change mitigation, not adaptation policies.

- Only examining evaluations of policies reported as climate policies by cross-checking with reports submitted to the UNFCCC (e.g. the latest National Communications submitted by Parties to the UNFCCC). Evaluations of policies were considered eligible when they included a specific reference to climate change mitigation, even if the latter was not primary or specific objective of the policy.

- Excluding purely academic articles.

- Excluding non-systematic analyses such as position papers by NGOs, industry groups, and trade associations

\footnotetext{
${ }^{6}$ The Member State shares of total greenhouse gas emissions in the EU28 in 1990-2016 were the following: Germany 21.1\%, UK 11.6\%, France 10.7\%, Czech Republic 3.0\%, Greece 2.1\%, and Austria 1.8\%; http://ec.europa.eu/eurostat/statistics-explained/index.php/

Greenhouse_gas_emission_statistics last accessed on 28 March 2019.
}

whose primary purpose is not considered to be evaluation as such but advocacy for policy change.

- Focusing on the EU-level and national policies, excluding purely sub-national policies.

- Looking only at documents that were made available to the public.

Of course, these choices can influence the results of collecting and aggregating evaluations. For instance, excluding academic articles avoids double counting between different versions of the same paper at different stages (e.g. first published as a working paper or report, followed by an academic article with essentially the same contents). It also allowed us to focus on the content of Member States' reports and official policy evaluations and whether and to what extent these represented rigorous evaluation practices. At the same time, this decision risks lowering the total number of evaluations covered and may also influence the number of evaluations we classified as "independent".

In the next step, following the eligibility criteria outlined above, we gathered relevant evaluations by researching relevant sources such as national governments websites, university websites, well-established national consultancies and research institutes and repositories including EU and UNFCCC databases.

In the third step, we coded key information from the evaluations with a view to creating a comprehensive set of information (see Appendix 1 in [22]). For this purpose, a common template was developed drawing on the template used by Huitema et al. [6].

The information collected for each of the evaluations was aggregated, focusing on the following features and design choices (following [6]): (1) the year of publication; (2) the affiliation of authors; (3) commissioning bodies of evaluations; (4) sectoral coverage; (5) the nature of the evaluation (reflexivity); (6) evaluation methods used; (7) evaluation criteria used; and (8) whether political recommendations were made (see Appendix). The aggregation process also helped to verify the information collected, spot gaps and inconsistencies, and, in some cases, led to the exclusion of evaluations that, on closer inspection, did not meet the eligibility criteria.

While focusing on these features and design choices allowed a systematic analysis of climate policy evaluation practices in the EU and some of its Member States, several caveats are in place. First, the number of evaluations found is likely to be non-exhaustive, for instance because evaluations are not always publicly available. Second, the act of coding evaluations means that a degree of subjectivity is inevitable. For example, evaluations do not always clearly spell out which criteria or methods are used, and judging whether an evaluation is reflexive in nature is not always straightforward. We sought to address this concern 
by offering detailed guidance to the coders working in a decentralised manner (see Appendix 1 in [22]). Some discretion was left to the individual coders on practical choices (see also [6]). Nevertheless, systematically applying the coding template allowed us to draw some conclusions concerning EU policy evaluation practices. The following section reports and analyses results of coded evaluations in a way comparable to Huitema et al. [6].

\section{Results}

\section{General information}

In total, our sample consisted of 236 evaluations, distributed amongst Member States as displayed in Table 1. The variation in the number of evaluations implies a discrepancy in evaluation practices across Member States for reasons other than limited capacity as discussed earlier. Lists of sampled evaluations can be found in Appendix 2 of [22].

In comparison, the sample size of evaluations covered by Huitema et al. [6] - which also included adaptation policies and academic articles - was 259 , ranging from the EU (105 evaluations) and the UK (78 evaluations) to Portugal (10 evaluations) and Poland (6 evaluations). The diversity of the new sample for 2010-2016 is similar to those of the old sample for 1998-2007, although the average number of evaluations (compared to the number of years covered) is comparatively higher (33.7 evaluations per year compared to 25.9 evaluations per year), even though the sample in Huitema et al. [6] included studies covering adaptation, and also included journal articles.

\section{Timing of publications}

The number of evaluations continued to increase towards 2015, except for 2013, and then declined by more than half (Fig. 1). It is unclear whether the year 2016 is exceptional or signals a changing trend. It is possible that a number of evaluations were completed in 2016 but not yet published.

The number of evaluations could be linked to specific policy developments and requirements at international, EU and national levels. Nearly half (47\%) of the total evaluations were published in the years 2014 and 2015. These years can be regarded as important milestones to evaluate existing policies in preparation for two major policy events. One is the submission of intended nationally determined contributions (INDCs) to the UNFCCC, which were due in the first quarter of 2015. The other is the launch of the Energy Union in Europe in 2015. The evaluations in the third highest year, 2012, include the first

Table 1 Evaluations per jurisdiction

\begin{tabular}{lcccccccc}
\hline Countries & EU & Germany & $\begin{array}{l}\text { United } \\
\text { Kingdom }\end{array}$ & Greece & Austria & France & $\begin{array}{l}\text { Czech } \\
\text { Republic }\end{array}$ \\
\hline $\begin{array}{l}\text { Total } \\
\text { number of } \\
\text { evaluations }\end{array}$ & 70 & 59 & 64 & 20 & 8 & 10 & 5 & 236 \\
\hline
\end{tabular}

carbon market report at the end of the second phase of the EU ETS, and sectoral analyses of non-ETS sectors.

The new sample for 2010-2016 remained mostly in the range of around 30-60 evaluations per year. This falls between the low level of evaluation activities (0-30 evaluations per year) in 1998-2004 and the high level of activities (80-90 evaluations per year) in 2005-2006 (Figure 1 in [6]).

\section{Affiliation of the authors}

Figure 2 shows the affiliation of authors, highlighting that universities or research institutes, followed by government bodies, were responsible for the clear majority of evaluations. ${ }^{7}$ Government bodies rather than universities or research institutes only contributed most to evaluations as authors in the EU and the Czech Republic.

The previous study by Huitema et al. [6] also ranked universities or research institutes (about 135 evaluations) on top, but followed by commercial consultancies (50-60 evaluations) and international organisations (20-30 evaluations) (Figure 2 in [6]). A fewer number of government bodies authored policy evaluations.

\section{Commissioning bodies}

Figure 3 shows that most evaluations were commissioned by government bodies. ${ }^{8}$ The second highest number of evaluations does not fall under any of the specified categories, i.e. others. This category may include any evaluations for which the commissioning bodies could not be identified. It is possible that NGOs were underrepresented in the sample due to the eligibility criteria. For example, certain ex-post evaluations carried out for their internal purposes may well have been excluded from the sample.

Huitema et al. [6] do not provide details about the breakdown of commissioning bodies but differentiate whether the relevant evaluation was commissioned or not. Thus, the new sample for 2010-2016 cannot be adequately compared with the study with respect to this question.

\section{Sectors}

Information collected with regard to the sectoral coverage of evaluations was classified under the following sector categories, based on categories established by the Intergovernmental Panel on Climate Change (IPCC): energy (including buildings), industry/industrial processes, waste, land use, land-use change and forestry (LULUCF), agriculture, transport and cross-sectoral.

Figure 4 reveals that evaluations in the energy sector are dominant in our sample, ${ }^{9}$ with 171 evaluation

\footnotetext{
${ }^{7}$ Evaluations may be counted under more than one category.

${ }^{8}$ Evaluations may be counted under more than one category.

${ }^{9}$ Evaluations could be - and have been - counted under more than one category, which is the reason for the divergence of the total number of evaluations in our sample (236) and the total number of evaluations in Figure 4 (367).
} 


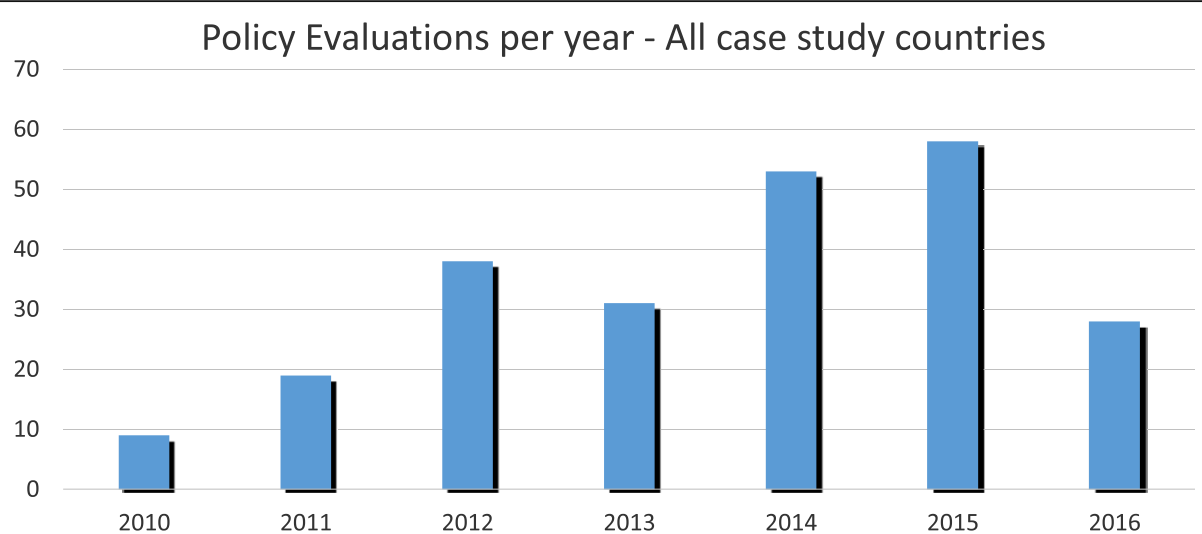

Fig. 1 Evaluations per year

entries covering the sector where multiple answers were possible. While this large share might be due to the fact that we included the buildings sector in the energy sector (as does the UNFCCC), this finding is in line with a study done by the EEA, which also showed that most energy and climate policies of Member States focused on the energy sector [23]. This was followed by cross-sectoral evaluations (61 entries), industry/industrial processes (51) and transport (48). This pattern is common to most of the jurisdictions covered, except the EU, which had a relatively higher share of cross-sectoral approaches than Member States. Moreover, some sectors, such as the agricultural, waste and LULUCF sectors, are clearly under-represented. LULUCF evaluations have been particularly scarce, possibly because the sector was not accounted for in the EU-wide emission reduction target up to 2020 .

Looking at specific jurisdictions, the share of the energy sector is particularly high in the UK and Germany (Fig. 5).$^{10}$ it is noteworthy that in our sample, evaluations carried out on the EU level seem to roughly reflect the cross-sectoral distribution of actual emissions, ${ }^{11}$ while the Greek evaluations focus primarily on the energy sector.

The sectoral spread in the sampled evaluations can be compared with the sectoral shares of actual greenhouse gas emissions in the EU28 in 2015, i.e. energy (55\%), transport (23\%), industry (8\%), agriculture (10\%), and waste (3\%) [37].

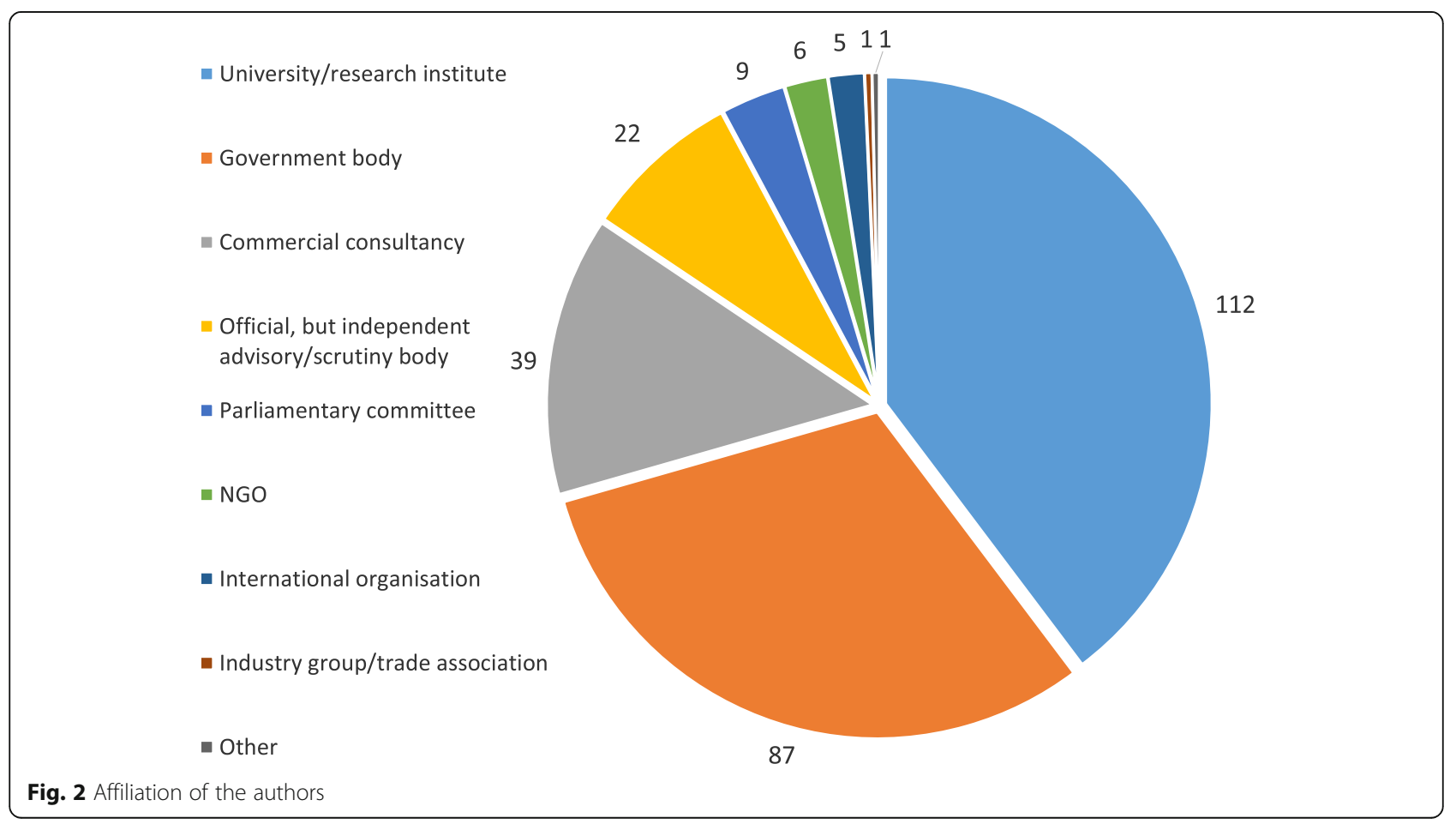




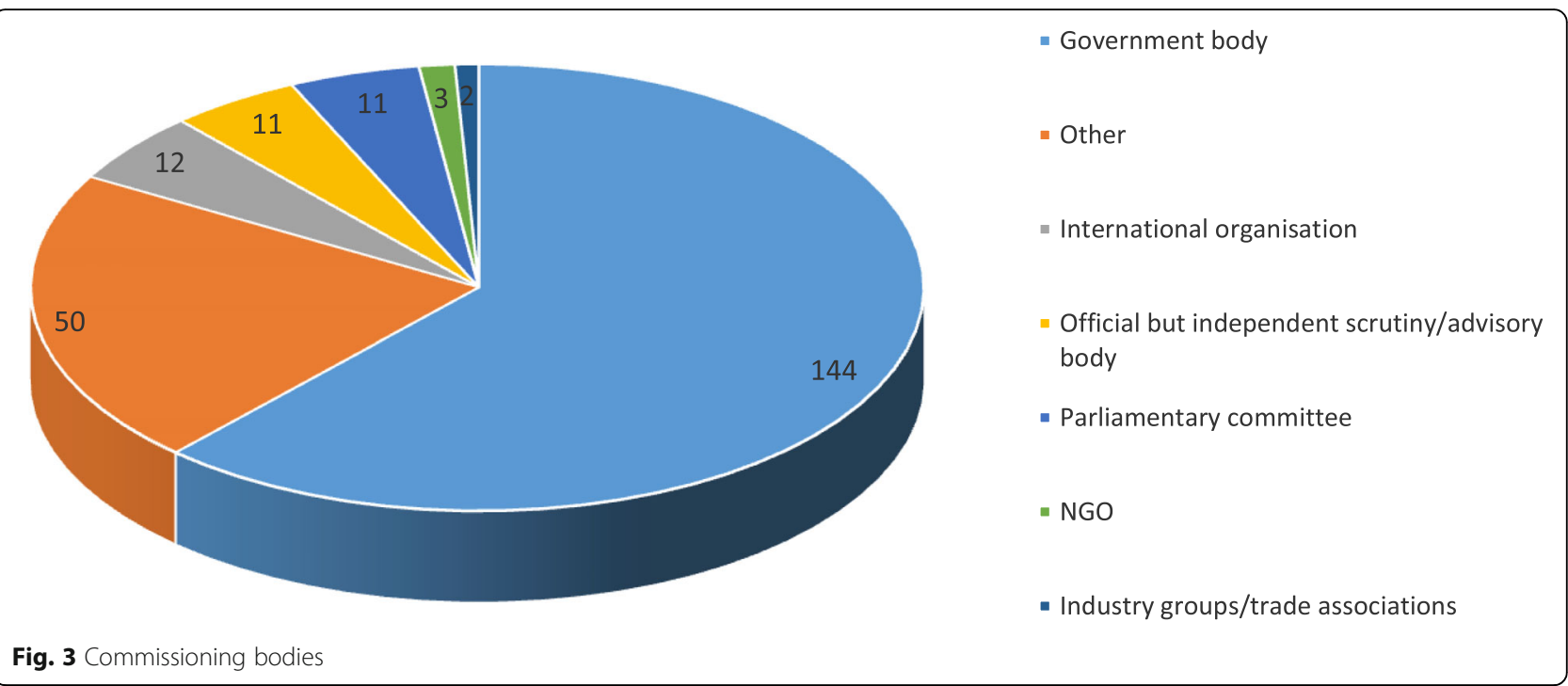

The aggregated data suggests that both the energy and industry sectors are represented to a higher extent than their actual shares of emissions, despite the challenges of delineating specific sectors, ${ }^{12}$ and the multiple counting. By contrast, transport, agriculture and the LULUCF sectors are under-represented given their actual shares of emissions.

The strong focus on the energy sector in climate change mitigation policies corresponds to observations made by Bößner et al. [24] regarding the information available in international climate change mitigation policy databases. Of all the international databases analysed, the large majority contained information about energy policies, but only a fraction conveyed any information on mitigation policies in the agricultural or waste sector.

Huitema et al. [6] do not provide for a sectoral breakdown per country, meaning that a direct comparison is not possible.

\section{Reflexivity}

Policy evaluations can be conducted in a reflexive or non-reflexive manner. While the latter entails answering the question whether objectives of a given policy were reached according to certain criteria, a reflexive policy evaluation questions the objective and the chosen means to reach this objective critically and tries to address questions like whether the policy itself was/is justified.

\footnotetext{
${ }^{10}$ Evaluations may be counted under more than one category. Also, UK waste and agricultural policies have been addressed by a few crosssectoral studies and were classified as such.

${ }^{11}$ Evaluations in France and Austria also seem quite evenly distributed, but the sample size was quite small.

${ }^{12}$ However, grouping emissions into different sectors is not standardised; the European Commission places all "combustion from fuels" under the energy category including "combustion from construction and manufacturing" which might be placed under the "industrial processes" category by other institutions.
}

In the sample, the majority of the evaluations (204 evaluations, 86\%) are found to be non-reflexive.

The high share of non-reflexive evaluations is comparable to the share (82\%) in the 1998-2007 sample [6].

However, a closer look at each country shows mixed results across jurisdictions. On the one hand, the EU, Germany, the UK and Austria have the highest shares of non-reflexive evaluations (70 evaluations for EU and 59 evaluations for Germany), 83\% (53 out of 64 evaluations for UK) and 75\% (6 out of 8 evaluations for Austria). On the other hand, Greece has an even split (10 evaluations each) while France and the Czech Republic have reflexive evaluations at $60 \%$ (6 out of 10 evaluations for France; 3 out of 5 evaluations for the Czech Republic).

\section{Evaluation methods}

A closer look at the methods used to evaluate policies shows that most of evaluations used "documentary analysis" (153 entries). In a decreasing order, other methods used were "modelling, regression analysis or time series analysis" (88), "public opinion polls, user surveys, stakeholder analysis, feasibility assessments or expert interviews" (85) and "cost benefit analysis, cost-effectiveness, multi-criteria analysis, feasibility analysis or risk analysis" (44) (Fig. 6). ${ }^{13}$ In terms of stakeholder involvement, it can be assumed that most of the methods applied are neither participatory nor interactive, except for the category of "public opinion polls, user surveys, stakeholder analysis, feasibility assessments or expert interviews".

The above three types of methods also scored high in [6], which placed 181 evaluations out of the total 259 in

\footnotetext{
${ }^{13}$ Evaluations may be counted under more than one category.
} 


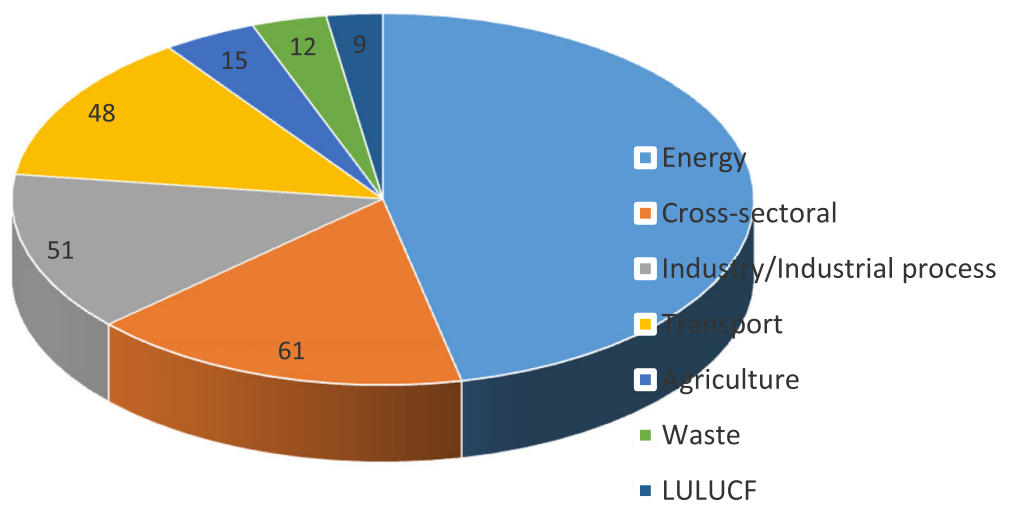

Fig. 4 Sectors covered, all jurisdictions

the category "documentary analysis", and 93 evaluations in the "modelling" category.

Looking at the largest jurisdictions in terms of population, it is interesting to note that Germany relies mostly on "modelling, regression or time-series analysis" (59\%), while the UK uses proportionally more "public opinion polls, user surveys, stakeholder analysis, feasibility assessments or expert interviews" (52\%) than other countries (Fig. 7).

\section{Evaluation criteria}

Following Huitema et al. [6], we identified the evaluation criteria for each study. Table 2 illustrates some examples of questions associated with each of the evaluation criteria we distinguished.

The overwhelming majority of evaluations assessed policies against their "effectiveness and goal attainment" (194), followed by "cost-effectiveness" (74), "efficiency" (50), "legality or legal acceptability" (47), "coordination with other policies" (40), "fairness" (33) and "legitimacy" (23). This shows that evaluations opt for assessing policies in a technical and/or economic manner, while more qualitative criteria such as fairness or legitimacy were addressed in a limited number of jurisdictions only. As above, this question allowed for multiple answers (Fig. 8). ${ }^{14}$

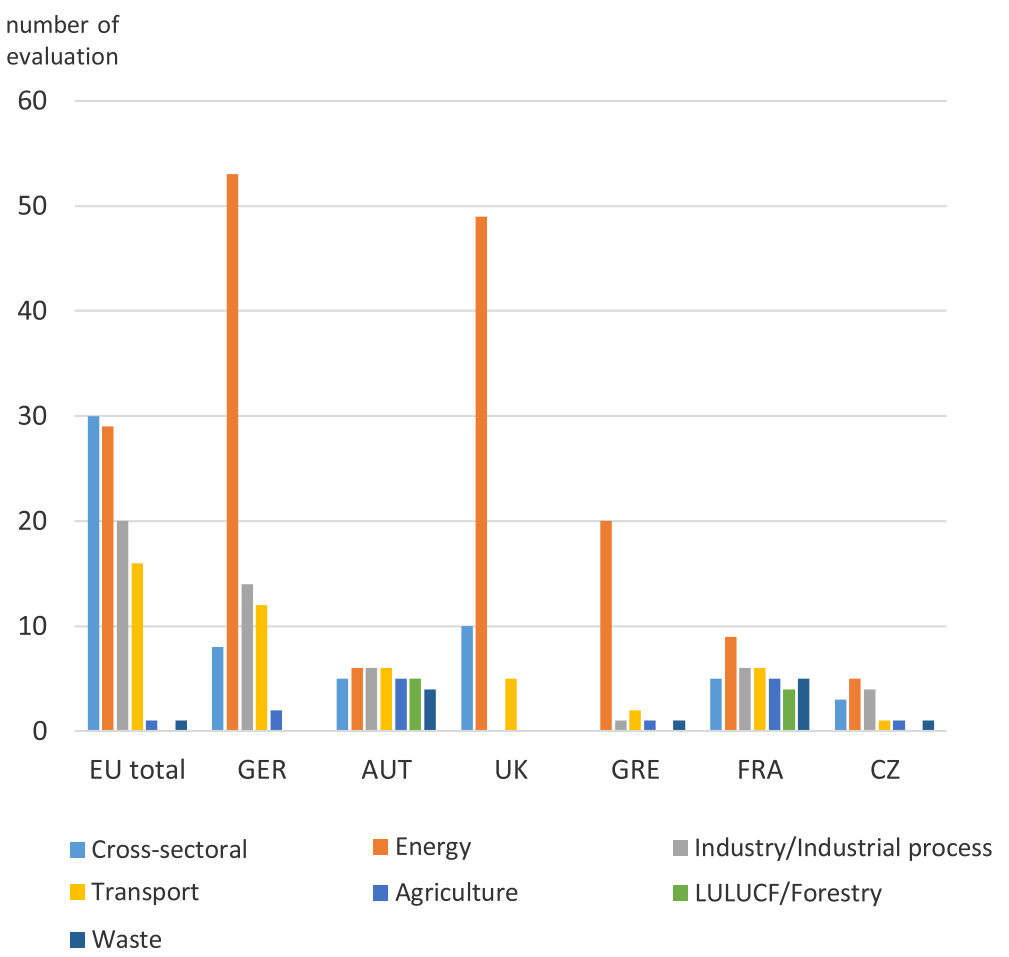

Fig. 5 Sectors covered by jurisdiction 
The above results are not that different from the sample in [6], which also found that the majority of the evaluations focused on evaluating the effectiveness and goal attainment of policies.

Broken down for each jurisdiction, it is noteworthy that all the French evaluations and almost all of the EU evaluations (68 entries) address "effectiveness and goal attainment". The EU-level evaluations show a higher-than-average share of "cost-effectiveness" (35) and "legality or legal acceptability" (30). Moreover, while most of the UK evaluations focus on "effectiveness", "cost-effectiveness" and "efficiency", the country also has a higher-than-average share of evaluations addressing "policy coordination", "fairness" and "legitimacy" (14, 17 and 10 respectively) (Fig. 9).

\section{Presence of political recommendations}

Finally, close to half (44\%) of the evaluations made political recommendations. A closer look, however, shows mixed results across jurisdictions. Generally, a high share of evaluations in the Member States made political recommendations, whereas the share of political recommendations in the $\mathrm{EU}$ was rather low (5 out of 70 evaluations, i.e. $7 \%$ ).

\section{Discussion}

Several inferences can be drawn on the basis of the metaanalysis results presented in the previous section. First, the number of evaluations fluctuates year-by-year, but seems to be linked to specific climate policy developments and events at the national, European, and international levels. For example, evaluations increased significantly before countries first published their INDCs, and when the European Commission launched its Energy Union initiative. This implies that international climate policy events - including not only the regular and review reporting already part of the UNFCCC regime, but also the new global stocktake due to start in 2023 and its predecessor, the Talanoa Dialogue which was launched in 2018 - may influence climate policy evaluation activities by setting milestones. Moreover, the five-yearly preparation of NDCs by all parties to the Paris Agreement is likely to spur climate policy evaluations, as evaluations can help the EU as a whole and Member States determine what level of ambition is adequate for their future policies.

Second, the largest group carrying out the sampled evaluations were universities and research institutions. However, a relatively large number of evaluations were carried out by government bodies, showing a significant increase from the sample of Huitema et al. [6]. These findings are interesting in light of the distinction in policy evaluation theory made between "formal" and "informal" evaluations

\footnotetext{
${ }^{14}$ Evaluations may be counted under more than one category, thus allowing the sum of each category to exceed the number of 236 evaluations.
}

[14]. The key distinction here is that formal evaluations are carried out or driven (e.g. commissioned) by governments, or those responsible for the policy, whereas informal evaluations are driven by other societal actors. Our analysis also found that government bodies are responsible for commissioning the large majority of evaluations in the sample. This suggests that while a large part of evaluations continues to be of an informal nature, formal evaluations may be on the rise.

Third, the dominance of the energy sector could be explained by the fact that the sector is responsible for the largest share of emissions in Europe, and has the largest mitigation potential. ${ }^{15}$ Moreover, emissions from the sector can be measured, monitored, quantified and verified more easily than other sectors. ${ }^{16}$ Another possible reason is that delivering emission reductions in the energy sector is considered more cost-effective than in other sectors, such as transport (e.g. "to promote reductions of greenhouse gas emissions in a cost-effective and economically efficient manner", [25]; see also [26]). Lastly, the energy sector has additional mitigation potential through energy savings by end-users $([27,28])$ in addition to those by producers and distributors.

As far as the over-representation of the industry sector in the evaluations in relation to their actual shares of emissions is concerned, one explanation might be the sensitivity of the sector for the overall economy, particularly in Member States such as Germany in which industry is an important economic sector and where many jobs depend on the performance of and policies directed at this sector. Moreover, there are remaining concerns about the possible impact of EU climate policies and instruments such as the EU ETS on competitiveness and carbon leakage [29].

However, the low number of any policy evaluations in the agriculture, waste or LULUCF sectors is an area that requires further investigation. Emissions from these sectors are still covered less by EU mitigation policies because until recently the EU emission reduction targets did not take into consideration the LULUCF sector, which means the sector was outside the scope of the major policy initiatives for the period until 2020 [38]. Or the nature of the sectors may mean that mitigation policies and policy evaluations are subsumed under larger policy initiatives (e.g. on sustainable agriculture or sustainable forest management) where climate change mitigation is but one of several policy goals. In any case, in the EU where, for example, the agricultural sector represents about $10 \%$ of greenhouse gas emissions [39], it is important to understand how well policies covering different aspects of these emissions have worked individually

\footnotetext{
${ }^{15}$ The energy sector accounted for $55 \%$ of the total greenhouse gas emissions in EU28 in 2015.

${ }^{16}$ The energy sector has been covered by the EU emissions trading system (ETS) since 2005. See [25, 26].
} 


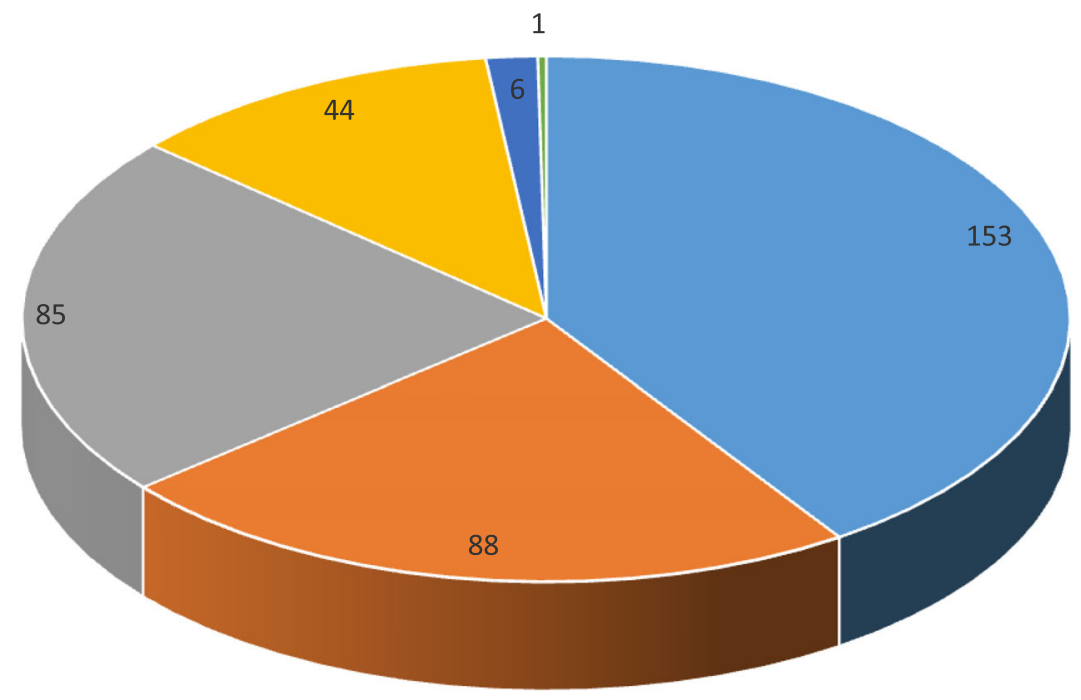

- Documentary analysis

- Modelling, regression analysis, time series analysis

- Public opinion polls, user surveys, stakeholder analysis, (political) feasibility assessments, expert interviews

- Cost-benefit analysis, cost-effectiveness analysis, extended cost-benefit analysis, multicriteria-analysis, (financial) feasibility analysis, risk analysis

- Not specified/Unclear

- Social experimentation

Fig. 6 Evaluation methods, all jurisdictions

and how different policies have influenced each other, e.g. how agriculture, rural development, energy, and climate policies affect each other on bioenergy or biofuel production.

Fourth, the sample revealed that the vast majority (more than two-thirds) of the evaluations are not reflexive or participatory, confirming the findings in [6]. Besides the small number of reflexive evaluations (i.e. those evaluations which examine the policy and its objectives more critically), most evaluations assessed policies against the criteria such as "effectiveness and goal attainment" and/or "cost-effectiveness". Moreover, with the exception of the UK and Greece, evaluations hardly addressed questions related to the fairness or legitimacy of policies. Yet knowing how a certain policy actually performed against these criteria - particularly legitimacy -will be important for understanding the state (acceptance and distribution) of public support for existing policies. While methods such as public opinion polls and stakeholder analyses have been well integrated in the EU evaluation practices and carried out relatively often, simple documentary analysis as well as modelling efforts still remain the methodology of choice for most (45\%) evaluations assessed. This suggests that a large part of evaluations is not participatory in nature.

However, using evaluation criteria other than effectiveness/goal attainment or cost- effectiveness and evaluation methods involving stakeholder participation are fraught with difficulties. For instance, assessing the fairness requires, first of all, the establishment of a benchmark of what can be considered "fair", how one can measure it, and - if the evaluation is to allow for comparisons - such benchmarks would need to be consistently applied. By contrast, the benchmarks for evaluations of effectiveness (e.g. tonnes of $\mathrm{CO}_{2}$ emissions reduced) or costeffectiveness (e.g. costs/tonne of $\mathrm{CO}_{2}$ emissions reduced) can - though need not ${ }^{17}$ - be relatively straightforward. In other words, the application of some criteria may involve important (subjective) choices on the part of the evaluator, ${ }^{18}$ which may make it more difficult to allow for comparative analyses. The use of participatory methods 


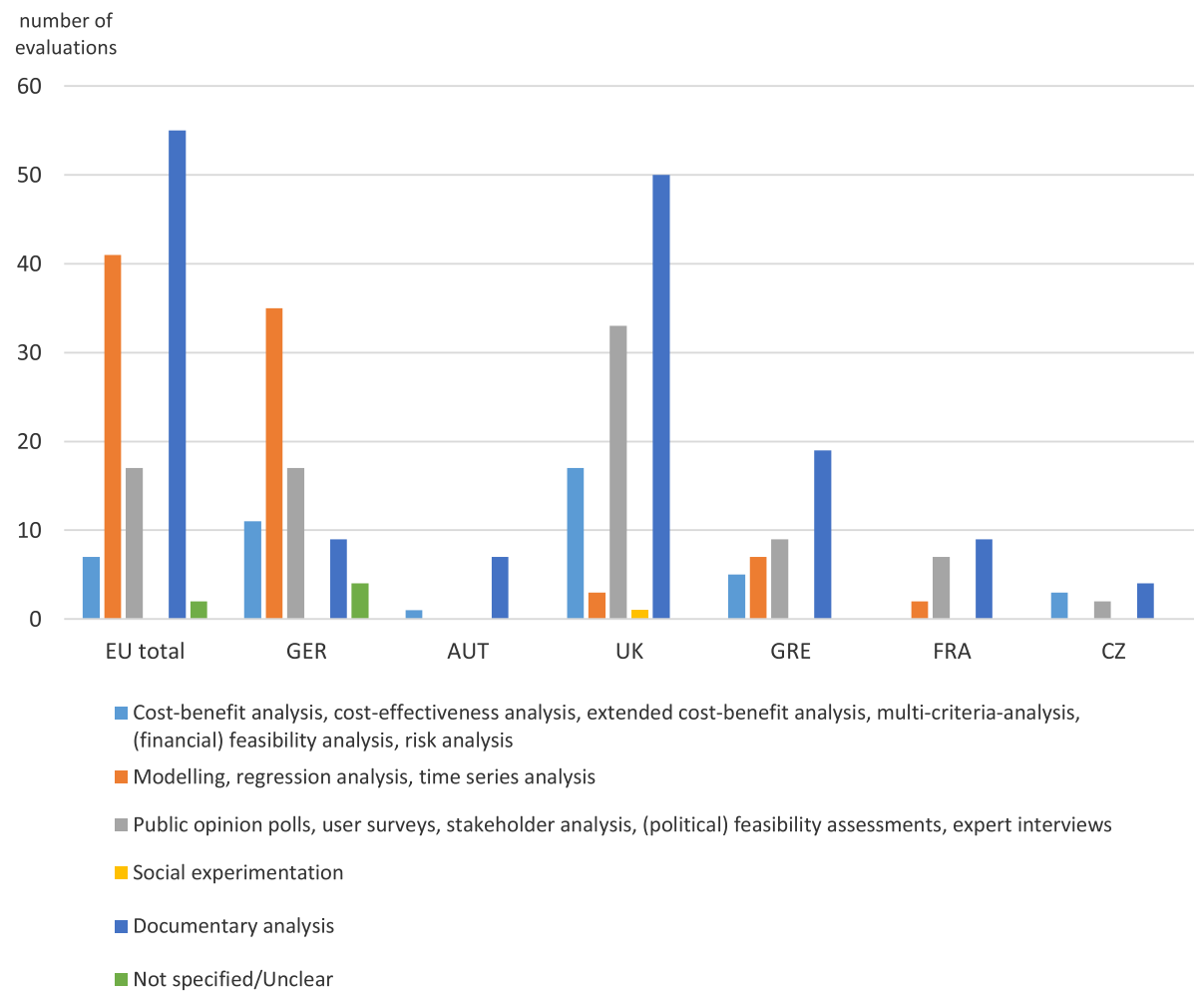

Fig. 7 Evaluation methods per jurisdiction

Table 2 List of criteria distinguished

\begin{tabular}{ll}
\hline Criterion & Examples of associated questions \\
\hline Goal attainment/ & Have specified goals been attained? \\
Can this be attributed to the policy? & E.g. Has the policy reduced absolute \\
& greenhouse gas emissions by the targeted level? \\
& How much of a given benefit is delivered \\
Cost-effectiveness & E.g. How many tonnes of carbon dioxide (CO ${ }_{2}$ ) \\
& emissions have been reduced \\
& for each Euro? \\
& Have the optimal goals been formulated? \\
& E.g. Is the price of carbon right? \\
Efficiency & How are the costs and benefits of a policy \\
Fairness & E.g. Does the EU emissions trading system (ETS) \\
& lead to windfall profits for power producers? \\
& Does the public accept the policies? Does the \\
policy meet criteria of democratic \\
accountability, such as transparency? \\
E.g. How much public support is there for \\
policies to promote wind power? \\
Is the policy well-coordinated with other policies? \\
E.g. How does the use of renewable energy \\
certificates interact with the EU ETS? \\
Is the policy compatible with legal rules and \\
principles? \\
E.g. Is the Member State's energy efficiency policy in \\
line with the Energy Efficiency \\
Directive or the Treaty on the Functioning of the \\
European Union? \\
Legal admissibility
\end{tabular}

Source: based on Fischer [11] and Huitema et al. [6] also faces particular challenges, including the costs of stakeholder engagement, and the needs for avoiding bias and ensuring representativeness (i.e. who participates).

Lastly, close to half of the evaluations presented political recommendations. There is a significant variance in the share of such recommendations between Member States on the one hand, and the EU on the other. The presence of political recommendations may depend on the role of evaluations envisaged in the relevant jurisdiction, specifically how far policy evaluations should go beyond the technical level, and how such evaluations should contribute to the legislative processes (e.g. providing evidence to policymakers in a closed process or directly submitting them to an open legislative process).

These findings have to be interpreted with care, due to limitations related to the eligibility criteria, such as the exclusion of academic publications, documents that are not publicly available and subnational policy evaluations. However, this new meta-analysis, combined with the previous one [6], enables researchers to track the long-term

\footnotetext{
${ }^{17}$ Although policy goals may seem undisputed, the policy goal as formulated may mask underlying contestations between different societal actors about what a specific policy should achieve.

${ }^{18}$ While this finding may apply to all criteria to some extent, it applies more strongly to those criteria where metrics for evaluations (e.g. amount of $\mathrm{CO}_{2}$ emissions reduced; costs per unit of $\mathrm{CO}_{2}$ emission reduction) are absent.
} 


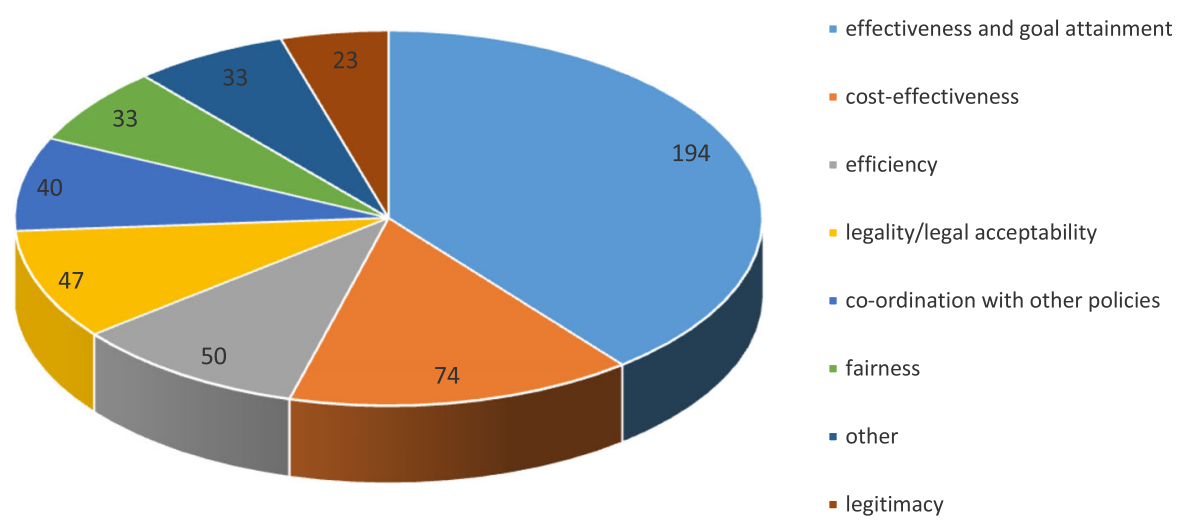

Fig. 8 Evaluation criteria, all jurisdictions

number of

evaluations

80

70

50

40

10

EU total

GER

AUT

UK

GRE

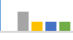

- effectiveness and goal attainment

efficiency

cost-effectiveness

- legality/legal acceptability

co-ordination with other policies

- legitimacy

- fairness

ather

Fig. 9 Evaluation criteria by jurisdiction 
trend in almost 20 years and understand the diversity of policy development across jurisdictions and sectors. This study shows that while evaluation of mitigation policies is quite advanced in some jurisdictions, there is still some room for improvement, not only in terms of the quantity of the evaluations but also in terms of their quality.

\section{Conclusions}

What insights does this meta-analysis provide for policymakers and the broader climate policy evaluation community? First, the meta-analyses discussed in this article and in [6] show that that there is no dearth of climate policy evaluations in Europe. The large and increasing number of evaluations might harbour some redundancies and overlaps, but it seems important to use this wealth of expost evaluations to support future EU legislative proposals and accompanying impact assessments.

To this end, existing and future policy evaluations could be saved in an EU-wide single, central and publicly accessible repository, which could be established and built on the existing infrastructure with support of the European Commission, including the Joint Research Centre, and the EEA. Such a repository would help render EU climate policies more robust in two ways. On the one hand, it could help researchers in carrying out similar assessments, avoid duplication of efforts, and allow for the sharing of lessons learnt in a more efficient manner. On the other hand, it could offer interested stakeholders - including policymakers, but also the general public - an initial indication of the performance of climate policy in the EU and its Member States, foster the exchange of evaluation practices, and suggest where further capacity building for climate policy evaluation may be needed.

Furthermore, the repository could offer a solid basis for studying - and improving - the quality of climate policy evaluations, and for examining whether evaluations are in line or at odds with each other. For instance, while evaluations may employ similar criteria (e.g. "goal attainment" or "cost-effectiveness"), they may be inconsistent in how those criteria are applied. A repository could thus help the climate policy evaluation community to assess existing evaluation practices, and where possible and appropriate, align them.

Although the sample of evaluations covered in both metaanalyses could offer a starting point for such a repository, additional efforts and resources would be needed to collect evaluations in other Member States, and to do so on an ongoing basis. The inclusion of ex-ante evaluations in such a repository could further be considered, so as to allow for a comparison of whether and to what extent the expectations set out in ex-ante evaluations (including impact assessments by the $\mathrm{EU})$ are consistent with the findings of ex-post evaluations.

Second, addressing evaluation criteria such as fairness and legitimacy as well as reflexivity in more jurisdictions would enhance policymakers' understanding of climate change mitigation policies across the EU. In our findings, fairness and legitimacy account for a smaller proportion of total evaluations than other criteria. Looking at specific jurisdictions, only the UK and Greece widely applies both criteria in expost evaluations. Their near absence in evaluations in other jurisdictions except fairness applied in Germany might be related to the lack of reflexivity in the sampled policy evaluations. If an evaluation does not critically question the policy objective or specific measures themselves or examine the grounds of their justification, criteria such as fairness and legitimacy will arguably be of less relevance.

However, to increase climate policy ambition, it will be important for policy evaluations to reflect on the adequacy of goals set in climate policies and on whether support of the policy (because it is seen as legitimate) is shared by a wide spectrum of stakeholders. In this respect, the new EU Governance Regulation [4] provides a framework for Member States to improve transparency and potentially address fairness or legitimacy in long-term policymaking and planning processes. A review of stakeholder positions on the European Commission's proposal for the Governance Regulation showed strong acceptance of the process [30]. At the same time, broadening the field of evaluators, as well as more inclusive and participatory approaches to policy evaluations could enhance their usefulness by giving space to a variety of actors (civil society organisations, businesses, citizens, etc.) to voice their views and share their experiences when analysing policies. Moreover, broadening the types of organisations carrying out or involved in climate policy evaluation could help policymakers reflect on their initial assessments, crystallise the points of contention or disagreements over policy designs, and correct any error or mistake made in previous decisions. The Governance Regulation [4] expects Member States to provide the public with early and effective opportunities to participate in and be consulted on the preparation of the national plans and to involve social partners in the preparation. Finally, it would be of interest to explore the debate on evaluation models and methods used in climate policy evaluations in relation to evaluators, political actors and relevant authorities. Doing so would acknowledge how evaluations would reflect political and social norms adhered to by different actors, which may affect the choice of models and methods.

Third, the EU, Member State governments and other actors commissioning evaluations should allocate sufficient resources to the coverage of relatively under-represented sectors, notably LULUCF and waste. Likewise, where possible, climate policy evaluators should pay more attention to including these sectors in their evaluations. This article affirms that there is an incongruence in the sectors targeted by the policy evaluations and the emissions shares which these sectors are responsible for. With the Paris Agreement's goal of net decarbonisation underscoring the role of 
negative emissions in achieving global temperature goals, mitigation in the land-use sector will likely only become more important. Thus, there is an urgent need for dedicating more resources to ex-post policy evaluations in the LULUCF, agriculture and waste sectors. Commissioning studies on the performance of policies in these areas - both at the EU-wide level, and for some Member States where these sectors are responsible for a relatively large share of emissions - can help address this gap. Such studies could help inform the EU as it explores the options to raise the level of ambition for the period beyond 2020 up to 2030 in its NDC to the Paris Agreement. Moreover, they may improve the evidence of what climate change mitigation policies have achieved in the $\mathrm{EU}$ and its Member States.

Despite some limitations and outstanding questions in need of further clarity, this meta-analysis has highlighted trends, patterns and focal areas of European evaluation practices in the area of climate change mitigation policies. Based on these outcomes, the article has pointed out where the evaluation practices could be further improved and contribute to wider discussions on policy evaluations and data analysis at the European and international levels.

\section{Appendix}

Table 3 Sustainable Earth Paper

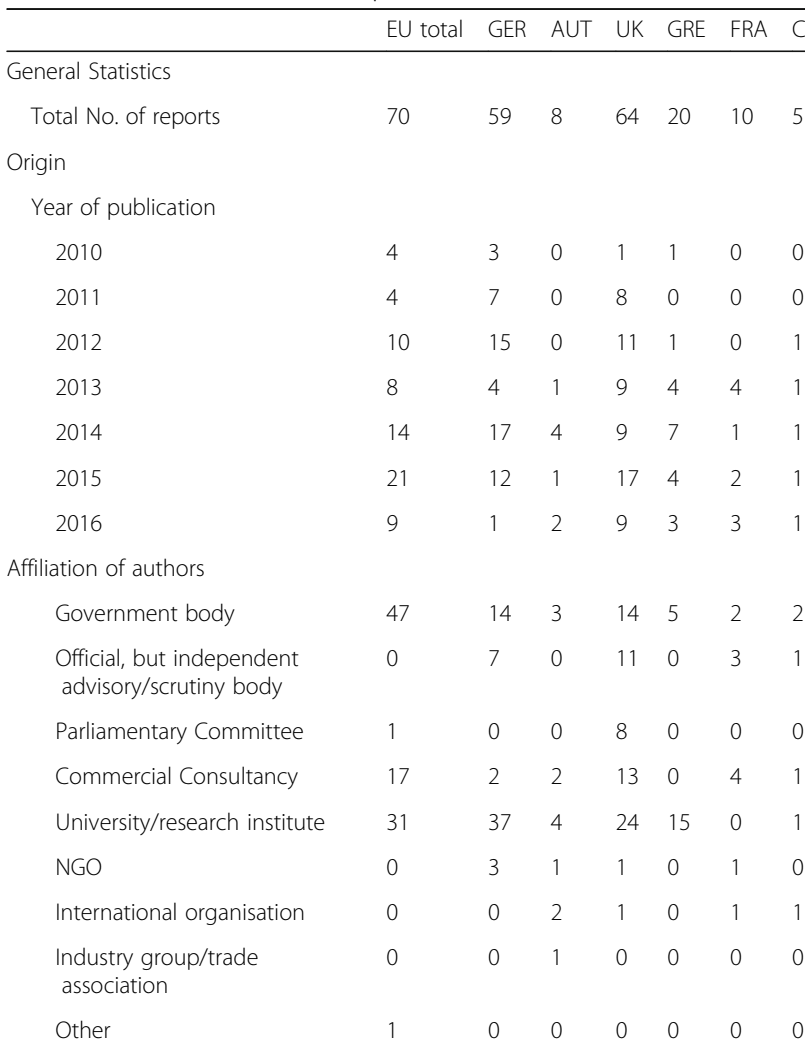

$\begin{array}{llllll}0 & 0 & 0 & 0 & 0 & 0\end{array}$
Table 3 Sustainable Earth Paper (Continued)

\begin{tabular}{|c|c|c|c|c|c|c|c|}
\hline & EU total & GER & AUT & UK & GRE & FRA & $\overline{C Z}$ \\
\hline \multicolumn{8}{|l|}{ Commissioned by } \\
\hline Government body & 66 & 26 & 5 & 29 & 7 & 7 & 4 \\
\hline $\begin{array}{l}\text { Official, but independent } \\
\text { scrutiny/advisory body }\end{array}$ & 3 & 6 & 0 & 1 & 0 & 1 & 0 \\
\hline Parliamentary Committee & 0 & 0 & 0 & 11 & 0 & 0 & 0 \\
\hline vinternational organisation & 1 & 0 & 2 & 0 & 6 & 2 & 1 \\
\hline $\begin{array}{l}\text { Industry groups/trade } \\
\text { association }\end{array}$ & 0 & 0 & 0 & 2 & 0 & 0 & 0 \\
\hline NGO & 0 & 2 & 0 & 0 & 0 & 1 & 0 \\
\hline Other & 1 & 26 & 1 & 22 & 0 & 0 & 0 \\
\hline
\end{tabular}

Sectors

$\begin{array}{llllllll}\text { Sectors } & 30 & 8 & 5 & 10 & 0 & 5 & 3 \\ \text { Cross-sectoral } & 29 & 53 & 6 & 49 & 20 & 9 & 5 \\ \text { Energy } & 20 & 14 & 6 & 0 & 1 & 6 & 4 \\ \text { Industry/Industrial Processes } & 16 & 12 & 6 & 5 & 2 & 6 & 1 \\ \text { Transport } & 1 & 2 & 5 & 0 & 1 & 5 & 1 \\ \text { Agriculture } & 0 & 0 & 5 & 0 & 0 & 4 & 0 \\ \text { LULUCF/Forestry } & 1 & 0 & 4 & 0 & 1 & 5 & 1 \\ \text { Waste } & & & & & & \end{array}$

Methods

Type of Evaluation

Reflexive

Non-reflexive

Evaluation method

Cost-benefit analysis, cost-

effectiveness analysis,

extended cost-benefit

analysis, multi-criteria analysis,

(financial) feasibility analysis,

risk analysis

Modelling, regression analysis, time series analysis

Public opinion polls, user

surveys, stakeholder analysis,

(political feasibility assessment,

expert interviews

Social experimentation

Documentary analysis

Not specified/unclear

Evaluation criteria

Effectiveness and goal attainment 68

Efficiency

Cost-effectiveness

Legality/legal acceptability

Co-ordination with other

policies

Legitimacy

Fairness

Other

Political Recommendations made?

Yes

No $\begin{array}{llllll}0 & 2 & 11 & 10 & 6 & 3\end{array}$

$\begin{array}{llllll}59 & 6 & 53 & 10 & 4 & 2\end{array}$

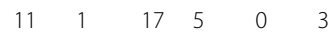

$35-120$

$\begin{array}{llllll}0 & 0 & 1 & 0 & 0 & 0\end{array}$

$\begin{array}{lllllll}55 & 9 & 7 & 50 & 19 & 9 & 4\end{array}$

$\begin{array}{lllllll}2 & 4 & 0 & 0 & 0 & 0 & 0\end{array}$

68

$\begin{array}{llllll}38 & 8 & 51 & 14 & 10 & 5\end{array}$

$\begin{array}{lllllll}20 & 7 & 0 & 20 & 3 & 0 & 0\end{array}$

$\begin{array}{lllllll}35 & 13 & 0 & 16 & 8 & 0 & 2\end{array}$

$\begin{array}{lllllll}30 & 0 & 2 & 6 & 8 & 0 & 2\end{array}$

$\begin{array}{lllllll}10 & 7 & 5 & 14 & 3 & 0 & 1\end{array}$

$\begin{array}{lllllll}1 & 1 & 2 & 10 & 8 & 0 & 1\end{array}$

$\begin{array}{llllll}9 & 0 & 17 & 6 & 0 & 0\end{array}$

$\begin{array}{llllll}14 & 0 & 9 & 1 & 0 & 0\end{array}$ $\begin{array}{llllll}34 & 5 & 36 & 14 & 7 & 3\end{array}$

$\begin{array}{lllllll}65 & 25 & 3 & 28 & 6 & 3 & 2\end{array}$ 


\section{Abbreviations}

$\mathrm{CO}_{2}$ : Carbon dioxide; EEA: European Environment Agency; ETS: Emissions trading system; EU: European Union; INDCs: Intended Nationally Determined Contributions; LULUCF: Land Use, Land Use Change and Forestry; MMR: Monitoring Mechanism Regulation; NDC: Nationally Determined Contribution; UNFCCC: United Nations Framework Convention on Climate Change

\section{Acknowledgements}

The authors thank Douglas Fraser for supporting the UK data collection and for helping prepare the coding template.

\section{Authors' contributions}

$N F, H v A$, and SB designed the research with inputs from SV, NAS, AF, EA, KW $A T$, and MtD. All authors performed the research. NF, HvA, and SB wrote the paper with inputs from SV, NAS, AF, EA, KW, AT, and MtD. All authors read and approved the final manuscript. SB visualised the data. The first three authors drafted at least one section or more. SV, NAS and AF largely accepted the draft, adding inputs. EA, KW, AT and MtD approved with comments or questions. NF, HvA, SB, and NAS revised the manuscript following peer review.

\section{Funding}

The article is based on the research undertaken under the CARISMA (Coordination and Assessment of Research and Innovation in Support of climate Mitigation Actions) project which received funding from the European Horizon 2020 Programme of the EU under the Grant Agreement No. 642242. At the time of project implementation, Bößner and van Asselt were affiliated with the Stockholm Environment Institute (SEI), Alberola with the Institute for Climate Economics (i4CE), and ten Donkelaar with ENVIROS.

\section{Availability of data and materials}

Supplementary data associated with this article are submitted as attachment.

\section{Ethics approval and consent to participate}

Not applicable.

\section{Consent for publication}

Not applicable.

\section{Competing interests}

The authors declare that they have no competing interests.

\section{Author details}

${ }^{1}$ Centre for European Policy Studies (CEPS), Place du Congrès 1, 1000 Brussels, Belgium. ${ }^{2}$ University of Eastern Finland Law School, Yliopistokatu 2 Fl-80101 Joensuu, Finland. ${ }^{3}$ Stockholm Environment Institute, Linnégatan 87D, 10451 Stockholm, Sweden. ${ }^{4}$ Centre for European Economic Research (ZEW), L 7, 1, 68161 Mannheim, Germany. ${ }^{5}$ University of Piraeus Research Centre (UPRC), 80, M. Karaoli \& A. Dimitriou St, 18534 Piraeus, Greece. ${ }^{6}$ ECOACT FRANCE, 35 rue de Miromesnil, 75008 Paris, France. ${ }^{7}$ University of Graz, Universitätsplatz 3, 8010 Graz, Austria. ${ }^{8}$ RICARDO, Prague Technical Centre, Palác Karlín, Thámova 11-13186 00, Praha 8, Czech Republic.

Received: 25 July 2018 Accepted: 15 October 2019

Published online: 12 December 2019

\section{References}

1. Schoenefeld JJ, Hildén M, Jordan AJ. The challenges of monitoring national climate policy: learning lessons from the EU. Clim Pol. 2018;18(1):118-28.

2. European Union (2013). Regulation (EU) No 525/2013 of the European Parliament and of The Council of 21 May 2013 on a mechanism for monitoring and reporting greenhouse gas emissions and for reporting other information at national and Union level relevant to climate change and repealing Decision No 280/2004/EC. [2013] OJ L165/13.

3. Umpfenbach K. Streamlining planning and reporting requirements in the EU energy union framework. Report for the European Climate Foundation. Berlin: Ecologic Institute; 2015.

4. European Commission (2016). Proposal for a regulation of the European Parliament and of the Council on the Governance of the Energy Union, amending Directive 94/22/EC, Directive 98/70/EC, Directive 2009/31/EC,
Regulation (EC) No 663/2009, Regulation (EC) No 715/2009, Directive 2009/ 73/EC, Council Directive 2009/119/EC, Directive 2010/31/EU, Directive 2012/ 27/EU, Directive 2013/30/EU and Council Directive (EU) 2015/652 and repealing Regulation (EU) No 525/2013. 23.2.2017 COM (2016) 759 final/2.

5. Spyridaki N-A, loannou A, Flamos A, Oikonomou V. An ex-post assessment of the regulation on the energy performance of buildings in Greece \& the Netherlands - a cross country comparison. Energy Efficiency. 2015;9(2):261-79.

6. Huitema D, Jordan A, Massey E, Rayner T, van Asselt H, Haug C, Hildingsson R, Monni S, Stripple J. The evaluation of climate policy: theory and emerging practice in Europe. Policy Sci. 2011;44:179-98.

7. Rossi P, Lipsey MW, Freeman HE. Evaluation: A systematic approach. 7th ed. Thousand Oaks: Sage; 2004.

8. Crabbe A, Leroy P. The handbook of environmental policy evaluation. London: Earthscan; 2008

9. Mickwitz P. Policy evaluation. In: Jordan A, Adelle C, editors. Environmental Policy in the EU: Actors, Institutions and Processes. London; New York: Routledge; 2013. p. 267-86.

10. Fournier DM. Evaluation. In: Mathison S, editor. Encyclopaedia of evaluation. Thousand Oaks: Sage; 2005. p. 39-40.

11. Fischer F. Evaluating public policy. Chicago: Nelson-Hall Publishers; 1995.

12. Spyridaki NA, Flamos A. A paper trail of evaluation approaches to energy and climate policy interactions. Renew Sust Energ Rev. 2014;40:1090-107.

13. Spyridaki N-A, Banaka S, Flamos A. Evaluating public policy instruments in the Greek building sector. Energy Policy. 2016;88:528-43.

14. Schoenefeld J, Jordan A. Governing policy evaluation? Towards a new typology. Evaluation. 2017;23(3):274-93.

15. Anglmayer I. Evaluation and ex-post impact assessment at EU level. Briefing, European Parliamentary Research Service, September; 2016.

16. Nilsson M, Jordan A, Turnpenny J, Hertin J, Nykvist B, Russel D. The use and non-use of policy appraisal tools in public policy making: an analysis of three European countries and the European Union. Policy Sci. 2008;41:335-55.

17. Mickwitz P, Birnbaum M. Key insights for the design of environmental evaluations. In: Binbaum M, Mickwitz P, editors. Environmental program and policy evaluation. New Directions for Evaluation; 2009. p. 105-12.

18. Haug C, Rayner T, Jordan A, Hildingsson R, Stripple J, Monni S, Huitema D, Massey E, van Asselt H, Berkhout F. Navigating the dilemmas of climate policy in Europe: evidence from policy evaluation studies. Clim Chang. 2010;101(3-4):427-45.

19. Hildén M, Jordan A, Rayner T. Climate policy innovation: developing an evaluation perspective. Environ Politics. 2014;23(5):884-905.

20. AEA, ECOFYS, Fraunhofer and ICCS. Quantification of the Effects on Greenhouse Gas Emissions of Policies and Measures: Final Report. ENV.C.1/ SER/2007/0019. Brussels: European Commission; 2009.

21. EEA (European Environment Agency). Environment and climate policy evaluation. Copenhagen: EEA; 2016.

22. Fujiwara, N., Bößner, S., van Asselt, H., Fraser, D., Voigt, S., Spyridaki, N.-A., ten Donkelaar, M., Alberola, E., Türk, A., and K. Williges (2017). D5.2: Meta-analysis of climate change policy evaluations in the EU and Member States. CARISMA Deliverable. http://www.carisma-project.eu/Portals/0/D5.2\%20Meta_analysis\%2 0of\%20climate\%20change\%20policy\%20evaluations\%20in\%20the\%20EU\%2 Oand\%20Member\%20States.pdf last Assessed on 13 July 2018.

23. Dejean F. Reporting on National Climate Action in the EU. Presentation at COP23 in Bonn, 08.11. 2017; 2017.

24. Bößner, S., van Asselt, H., Clochard, G.-J., Alberola, E., Türk, A., Spyridaki, N.-A., Fujiwara, N., van der Gaast, W. (2017). D5.1: report on climate change mitigation policy mapping and interaction. CARISMA deliverable. http:// www.carisma-project.eu/Portals/0/Documents/5.1\%20Report\%20on\%2 oclimate\%20change\%20mitigation \%20policy\%20mapping\%20and\%2 Ointeraction.pdf last Accessed on 13 July 2018.

25. European Union (2003). Directive 2003/87 of the European Parliament and of the Council of 13 October 2003 establishing a scheme for greenhouse gas emission allowance trading within the Community and amending Council Directive 96/61/EC, [2003] OJ L275/32.

26. European Union (2009a). Directive 2009/29/EC of the European Parliament and of the Council of 23 April 2009 amending Directive 2003/87/EC so as to improve and extend the greenhouse gas emission allowance trading scheme of the Community, [2009] OJ L140/63.

27. European Union (2009b). Decision No. 406/2009 adopted jointly by the European Parliament and of the Council on the effort of Member States to reduce their greenhouse gas emissions to meet the Community's greenhouse gas emission reduction commitments up to 2020, [2009] OJ L140/136. 
28. European Union (2012). Directive 2012/27/EU of the European Parliament and of the Council of 25 October 2012 on energy efficiency, amending Directives 2009/125/EC and 2010/30/EU and repealing Directives 2004/8/EC and 2006/32/EC, [2012] OJ L315/1.

29. Martin R, Muuls M, de Preux LB, Wagner UJ. On the empirical content of carbon leakage criteria in the EU emissions trading scheme. Ecol Econ. 2014;105:78-88

30. Ringel $M$, Knodt $M$. The governance of the European energy union: efficiency, effectiveness and acceptance of the winter package 2016. Energy Policy. 2018;112:209-20.

31. Van Asselt H, Weikmans R, Roberts JT. Pocket Guide to Transparency under the UNFCCC. Oxford: European capacity-building initiative; 2017. http:// www.eurocapacity.org/downloads/Pocket_Guide_to_Transparency_ UNFCCC.pdf last accessed on 13 July 2018

32. Ashford N, Renda A. Aligning policies for low-carbon systemic innovation in Europe. Brussels: CEPS and i24c; 2016.

33. European Union (2004). Decision No 280/2004/EC of the European Parliament and of the Council of 11 February 2004 concerning a mechanism for monitoring Community greenhouse gas emissions and for implementing the Kyoto Protocol, [2004] OJ L49/1.

34. EEA. National policies and measures on climate change mitigation in Europe in 2017, EEA report no 9/2018. Copenhagen: European Environment Agency; 2018.

35. Breitschopf, B., Schlomann, B., Voswinkel, F., and Broc, J-S. (2018). Identifying current knowledge, suggestions and conclusions from existing literature. H2020 EPATEE project report. Availabele at: https://epatee.eu/reports

36. Broc, J-S., Oikonomou, V., and Dragovic, M. (2018). Evaluation into practice: lessons learnt from 23 evaluations of energy efficiency policies. Volume I: Main findings. H2020 EPATEE project. Available at: https://epatee.eu/reports

37. http://ec.europa.eu/eurostat/statistics-explained/index.php?title=

Greenhouse_gas_emission_statistics_-_emission_inventories\#Trends_in_ greenhouse_gas_emissions last Accessed on 13 July 2018.

38. https://ec.europa.eu/clima/policies/forests_en last Accessed on 13 July 2018

39. http://ec.europa.eu/eurostat/statistics-explained/index.php?title=Agrienvironmental_indicator___greenhouse_gas_emissions last Accessed on 13 July 2018

\section{Publisher's Note}

Springer Nature remains neutral with regard to jurisdictional claims in published maps and institutional affiliations.

Ready to submit your research? Choose BMC and benefit from:

- fast, convenient online submission

- thorough peer review by experienced researchers in your field

- rapid publication on acceptance

- support for research data, including large and complex data types

- gold Open Access which fosters wider collaboration and increased citations

- maximum visibility for your research: over $100 \mathrm{M}$ website views per year

At $\mathrm{BMC}$, research is always in progress.

Learn more biomedcentral.com/submissions 